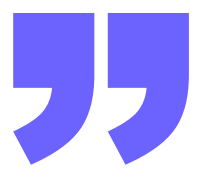

\title{
HIDDEN MESSAGES IN PINTEREST'S PUBLIC HEALTH ADVERTISEMENTS: A SEMIOTIC ANALYSIS
}

\author{
Ni Kadek Purnama Sari, Ni Wayan Suastini, I Wayan Juniartha \\ Mahasaraswati Denpasar University, Indonesia ${ }^{123}$ \\ nikadekpurnamasari98@gmail.com, suastini28@unmas.ac.id, \\ jjuniartha@gmail.com
}

\begin{abstract}
Advertisements are the media that used to promote a product, brand or service to a viewership to attract interest. The advertisement that used in this study is

Journal History

Submitted 10 th December 2021 public health advertisement that can be found in
Revised 11 th January 2022 Pinterest. Public health advertisement is aimed to Accepted 15 th January 2022 provide information to the people about the idea of Published 24 $4^{\text {th }}$ January 2022 healthy life that would be beneficial for society. Furthermore, this study combines verbal and nonverbal sign to give a certain effect to the advertisement. This study is aimed to describe the hidden messages that can be found in Pinterest's public health advertisements. This study uses semiotics theory by Saussure (1983) and

Keywords: theory of meaning proposed by Barthes (1977) that Semiotics, Signs, Verbal, supported by theory of color terms proposed by Nonverbal, Public Health Wierzbicka (1996). The data were collected through Advertisement observation method. In conducting this study, the descriptive qualitative method is used to analyze the data. The study concludes that both verbal and nonverbal signs found in each data carry hidden messages. In general, the advertisements convey the messages to encourage the readers to promote a healthy lifestyle that can be achieved through certain activities, namely, exercising regularly, eating healthy food, getting enough rest, and not doing the things that can harm their body as smoking cigarettes.
\end{abstract}




\section{INTRODUCTION}

Semiotic or the science of signs, is the study of the meaning of decisions Saussure (1972: 33). Semiotic includes sign and sign processes, indication, designation, similarity, meaning, and communication. Semiotic also studies of the structure and meaning of more specific language. Therefore, semiotic is a way to look at a deeper meaning in a sign.

According to Sobur (2004: 15), signs are tools that we can use to find a way in this world. A sign represents an object, particular state or condition, or quality. The sign also can represent an idea, feeling, thought, and action in communication. In our daily life, we always find a sign, for example, in an advertisement. The sign in an advertisement itself is used to inform something or promote something. It means signs or verbal and nonverbal itself used as the bridge of communication to the public. The process of communication is conveying one's thoughts and feelings to others in the form of a sign as a medium of communication. This sign can appear in a simple form such as a word or a complex form such as a novel or radio broadcast program Danesi, (2010: 27). One of the uses of semiotic is to look the meaning of the sign in advertisements.

Advertisement is a business that use sign and language to describe a reality. According to Wikipedia (n.d), advertisement promotes a product, brand, or service to a viewership to attract interest. Advertisement generally used a formal language. The sentences in advertisements are usually made short and straightforward. There are verbal and nonverbal sign combined by the creator to give a certain effect to the advertisement. Verbal and nonverbal signs are the two crucial elements in an advertisement.

According to Chandler (2002: 14) verbal sign in an advertisement is the text found in the advertisement. Those texts aim to get the reader's attention, make someone interested, stimulate, desire (make someone to buy something), create conviction, and make you do something. In contrast, nonverbal signs are symbols, icons, or pictures in the advertisement. There are a lot of advertisement can be found in Pinterest. Therefore, Pinterest is chosen as the main data in this study because some people generally do not understand the meaning of verbal and nonverbal, primarily found in signs.

The type of advertisement that is used explicitly in this study is public health advertisement. Public health advertisement is aimed to provide information or appeals to public about an idea of healthy life or movement for the benefit of society.

The language used in public health advertisements aims to persuade the readers to maintain their health by consuming healthy food, not smoking, not doing drugs, and not drinking alcohol. It is vital for us to 
know about the literal meaning of the sign itself and avoid any misunderstanding since some people find difficulties in understanding the meaning of signs. The writer analyzed verbal and nonverbal signs and its meaning in eight public health advertisements through this analysis.

\section{METHODS}

The data are obtained from Public Health advertisements that can be found in Pinterest. There are four advertisements used in this analysis entitled (a) Eat Right by Ateriet, (b) Healthy Lifestyle by Freepik, (c) Mental Health by Freepik, (d) Cigarette by Ateriet. The data are collected through observation, searching, and downloading public health advertisements from Pinterest, note-taking the verbal and nonverbal signs of the advertisements, and classifying the data regarding verbal and nonverbal signs. Thereafter, the data are analyzed by using the descriptive qualitative method. There are two main theories and one supporting theory used to analyze the data that have been collected. Those theories are including, the theory of Semiotics proposed by Saussure (1983), the theory of meaning by Barthes and supported by the theory of color term proposed by Wierzbicka (1996). Finally, the findings are presented both in formal and informal method.

\section{RESULTS}

\section{RESULT AND DISCUSSION}

The finding of this study shows that among 4 data there are 8 verbal signs and 12 nonverbal signs found. The table of data finding regarding to the verbal and nonverbal sign in Pinterest's public health advertisement is provided in the section below.

Table 1. The Occurrences of Verbal Signs and Nonverbal Signs in Pinterest's Public Health Advertisements

\begin{tabular}{|c|c|c|c|}
\hline No & Advertisements & Verbal Signs & Nonverbal Sign \\
\hline \multirow[t]{2}{*}{1.} & \multirow{2}{*}{$\begin{array}{l}\text { Eat Right } \\
\text { Advertisement } \\
\text { by Ateriet }\end{array}$} & $\begin{array}{l}\text { Eat Right for } \\
\text { Them }\end{array}$ & $\begin{array}{l}\text { Picture of broccoli in the form } \\
\text { of kidneys }\end{array}$ \\
\hline & & $\begin{array}{l}\text { They'll Stay } \\
\text { Right for You }\end{array}$ & Background with green color \\
\hline \multirow[t]{4}{*}{2.} & \multirow{4}{*}{$\begin{array}{l}\text { Healthy lifestyle } \\
\text { Advertisement } \\
\text { by Freepik }\end{array}$} & \multirow[t]{4}{*}{ Healthy lifestyle } & A person doing yoga \\
\hline & & & Various types of vegetable \\
\hline & & & The sun with yellow color \\
\hline & & & Background with white color \\
\hline \multirow[t]{2}{*}{3.} & \multirow{2}{*}{$\begin{array}{l}\text { Mental Health } \\
\text { Advertisement } \\
\text { by Freepik }\end{array}$} & The sun will rise & $\begin{array}{l}\text { Picture of human brain } \\
\text { blended with sunflower }\end{array}$ \\
\hline & & And we will try & Background with white color \\
\hline
\end{tabular}




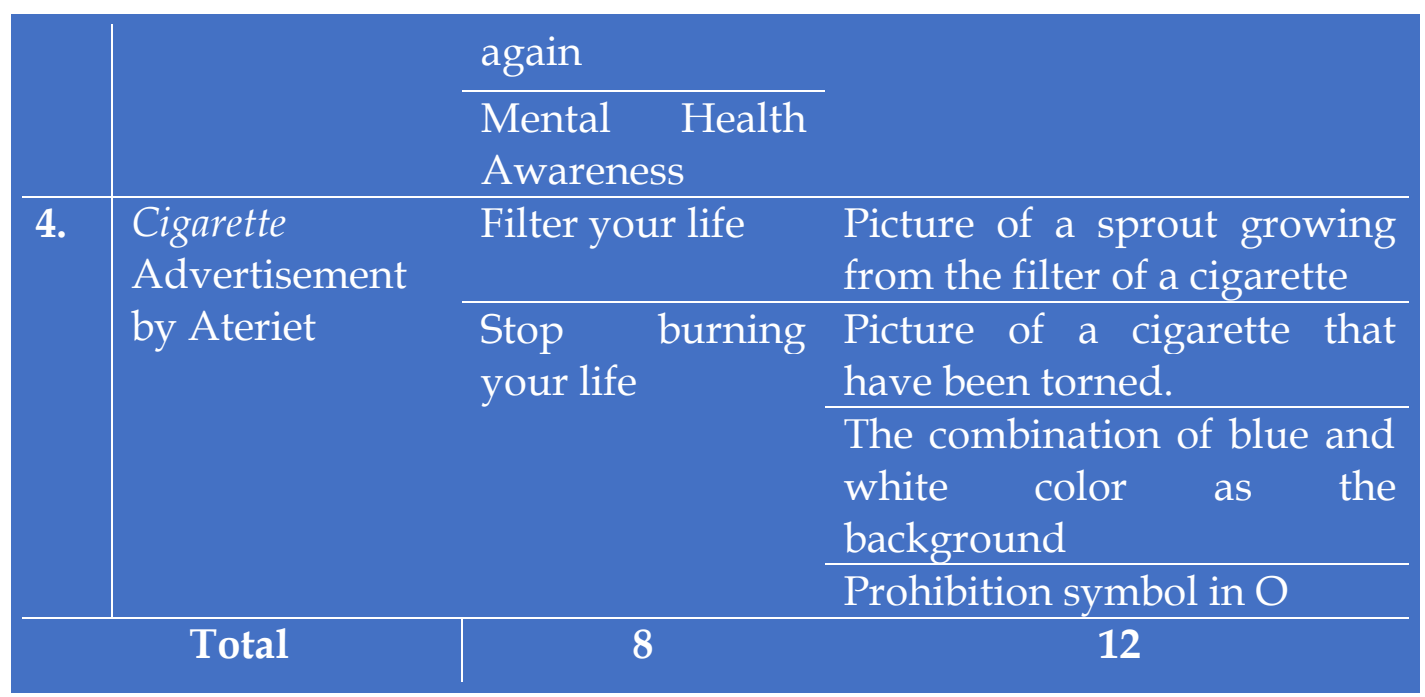

According to the table of data finding, the type of verbal sign that often appears is in form of sentences meanwhile, the type of nonverbal sign that often appears is in the form of pictures and colors. Furthermore, the verbal and nonverbal signs that have been found is analyzed according to the theory of Semiotics by Saussure (1983) and theory of meaning by Barthes that is also supported by theory of color term proposed by Wierzbicka (1996).

\section{DISCUSSION}

In this section, the data regarding verbal and nonverbal signs found in Pinterest's public health advertisements are analyzed to describe the hidden messages contained in the advertisement. The analysis of each data is presented as follows.

\section{A. The Analysis of Eat Right Advertisement}

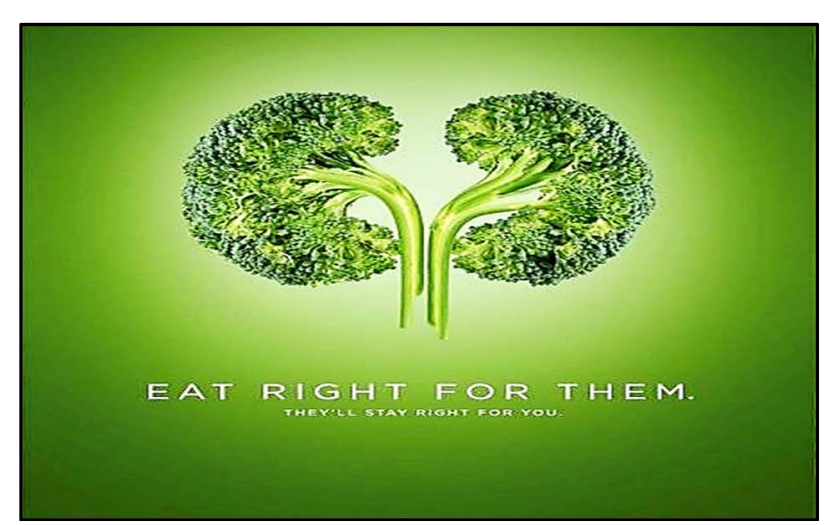

Figure 1. Eat Right Advertisement by Ateriet

(Source: pinterest.com) 
There are two verbal signs in this advertisement, which are namely: "Eat right for them" and "They'll stay right for you". The first verbal sign, "Eat right for them" denotes to have a meal that is right health-wise. The word 'them' is a substitute for 'kidneys' to represent human vital organs in the advertisement. Therefore, it implicitly delivers the message to the readers that is to choose the food they are about to eat wisely for the "kidneys" and all the other human organs to be healthy. The choice of food that is referred through the statement is the one that is healthy and contains various nutrients that is needed to fuel the organs properly.

The second verbal sign, "They'll stay right for you" is related to the previously mentioned one. Since 'they' is a pronoun that substitutes 'kidneys' or the human organs, it can be concluded that the sign denotes that the kidneys will continue to be in the particular state or situation for us. The sentence means that if we choose the right food as the fuel for our body, it will lead to our organs to be healthy. Therefore, it implicitly encourages the readers to always pay attention to the food they eat by considering the nutrients contained in it, which will be beneficial for all of the human organs, including our kidneys, to always be healthy and work properly.

In relation to the nonverbal sign, there are two nonverbal signs found in the advertisement. The first nonverbal sign is "picture of broccoli in the form of kidneys". This nonverbal sign denotes a meaning in which broccoli as one type of vegetables taking shape as kidneys, one of human's vital organs. According to the advertisement, the 'broccoli' represents a vegetable that is considered a healthy food and contains a lot of nutrients such as fiber, mineral, and vitamins needed by the body. In the picture, the broccoli is taking shape as one of the human organs. The "kidneys" represents the healthy state of human organs caused by eating the healthy kind of food that rich in nutrients. Therefore, the nonverbal sign above implicitly delivers a message regarding always eating healthy food that is rich in nutrients for our organs to work properly and the body to be healthy.

The last nonverbal sign is the background that is filled with green color. The denotation of green color is having the same color with grass and leaves in the trees. According to Wierzbicka (1996), green is associated with ambition, greed, and jealousy. Therefore, following the theme of the advertisement, the green color is related with ambition. In this case, the green background was implicitly telling the readers to always have the ambition to maintain their health by choosing the right kind of food that has many nutrients beneficial for the body.

\section{B. The Analysis of Healthy Lifestyle Advertisement}

There is only one verbal sign in the advertisement above that is "Healthy Lifestyle". The statement denotes a meaning regarding a life 
cycle that affects the human body to prevent being seriously ill. A healthy lifestyle includes consuming healthy food or maintaining a nutritious diet, exercising regularly, and having enough rest or sleep. In the advertisement, the verbal sign implicitly motivates the readers to promote a healthy lifestyle in their everyday lives, minimizing the risk of being sick and improving their well-being. The most important thing to remember is that we can make a great difference by changing our lifestyle to healthier one because the lifestyle we adopt will determine our long-term health condition. Therefore, it is necessary to be mindful of small behavioral changes that can affect our lives in the future and make sure it is the best one.

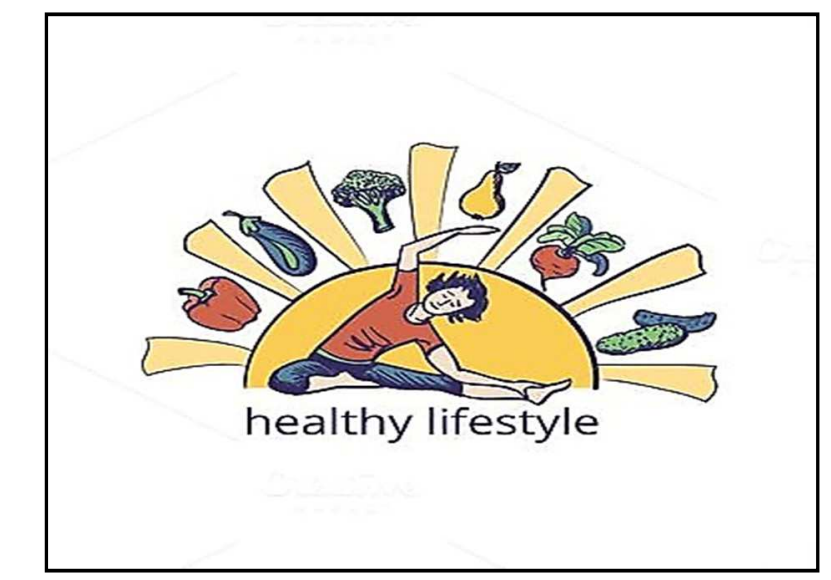

Figure 2. Healthy Lifestyle Advertisement by Freepik

(Source: pinterest.com)

In the advertisement above, there are several nonverbal signs found. The first one is a person doing yoga. It denotes a person who is doing yoga, the exercise for controlling the flow of breath and used by people who want to become fitter or to relax. Yoga is one among many exercises that is proven to be beneficial for the body. Unlike any other exercise, Yoga trains both the body and the mind because it involves breath control and simple meditation which helps the mind to be more relaxed. In the advertisement, however, Yoga exercise represents all types of exercises that people can do. The picture implicitly conveys the message to remind the readers to regularly exercise no matter what the type is. It is because if they are keep moving and it is done regularly, they will be healthy. Therefore, by regularly exercising, such as Yoga, people can maintain their bodies' health and minds.

The second nonverbal sign is various types of vegetable. The picture denotes vegetables as one type of healthy foods containing many nutrients needed by the human body, such as vitamins and minerals. Vegetables are known to be one option of healthy food needed by the body to work properly. Among many types of junk food that can be found everywhere nowadays, eating healthy kind of food such as vegetables is one solution so people can have a healthy body. Therefore, the nonverbal 
sign regarding the picture of various types of vegetables implicitly tells the readers to adopt a healthy lifestyle by consuming healthy food that is rich with nutrients such as vegetables.

The third nonverbal sign from the advertisement is the sun with yellow color. The denotation of the sign is the sun that literally in yellow color. Following the theme of the advertisement, it implies that people need to do sunbathing more often because it is beneficial for the body. Sunbathing in the proper hour such as in the morning will bring many benefits to the body because the morning sunlight contains vitamin D needed by our body to improve memory and provides protection against cancer and inflammations. This explanation is following the theory of color term by Wierzbicka (1996) since yellow as the color of the sun is associated with warmness.

The fourth and last nonverbal sign is the background with white color. White color denotes of having the color of fresh snow and of milk. Wierzbicka (1996: 303) states white color is associated with goodness, innocence, purity, and virginity. In relation with the theme of this advertisement, the white color symbolizes goodness and purity. It is because the color of the background implies the goodness and purity that people can achieve by adopting the healthy lifestyle mentioned in the advertisement in their life.

\section{The Analysis of Mental Health Advertisement}

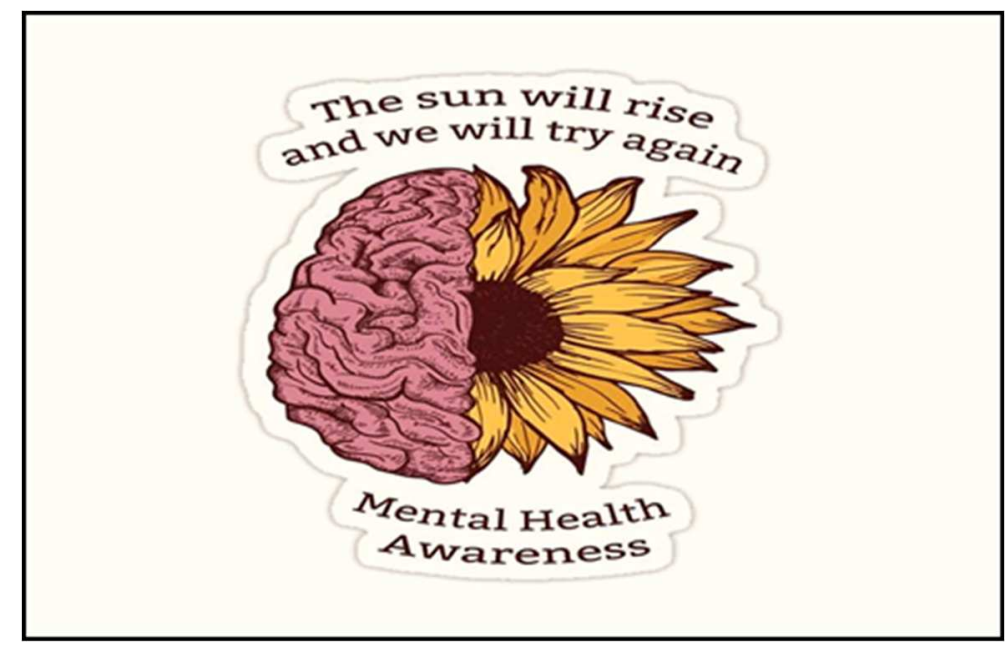

Figure 3. Mental Health Advertisement by Freepik

(Source: pinterest.com)

The advertisement above is related to the theme of mental health. Furthermore, there are three verbal signs can be found. The first verbal sign is "The sun will rise". The statement denotes the sun that will rise as the new day begins. "The sun" following the theme of the advertisement, represents hope. Therefore, the statement's implicit meaning is to encourage the readers that there is always hope for the people who think 
they have already failed for the mistake they have made. The "sunrise" is a representation of a new beginning. In other words, even we make mistakes and failures; we must continue our life by not giving up easily and staying positive to maintain our mental health.

The second verbal sign is "And we will try again" which denotes to keep trying. The statement is related to the previous verbal sign, which carries the meaning never to give up. It implies that even if we make mistakes in our lives, we should never give up easily and do the best things we can to move forward. It is because if we are worrying too much about our mistakes and our failure, it could burden the mind hence, our mental health would be affected. Our thoughts can directly affect the health of our body therefore if we overthink or always worrying about something, there would be side effects occurred in our body. Therefore, the only solution is to keep learning from the mistakes and trying to fix them in the future.

The third verbal sign is "Mental Health Awareness". The statement denotes the general understanding of one's mental health. It implicitly delivers a message to the readers that they are always aware of their own mental health. Mental health refers to our emotional and psychological state that affects how we think and behave. The one way to maintain mental health is by always thinking positively. There are many benefits that people can get by having a healthy or positive mind, such as boost the immune system, maintain heart health, cope with stress, reduce the risk of anxiety, and have longer life expectancy. Therefore, if we want to gain such benefits, we can start by always maintaining positive thoughts.

As the nonverbal signs, the advertisement carries two nonverbal signs. The first nonverbal sign picture of the human brain blended with sunflower. The denotation of the statement is a human brain that is displayed side to side with a sunflower. In accordance with the theme of the advertisement, that is mental health, the human brain represents the human mind that contains thought, memory and feeling while, the sunflower represents beauty and positive state. In the advertisement, both images are displayed to be blended as one. In that case, the picture implicitly describes the state of human mind if they maintain their mental health by always thinking positive. If our mind is healthy, it would reflect on our body and our life, which will be beautiful.

The second nonverbal sign is the background that is filled with white color. The color denotes of having the same color as of milk and snow. According to Wierszbicka (1996) white color is associated with goodness, purity, innocence, and virginity. Regarding the context of the advertisement, the white background implies the purity that our mind will achieve if we always maintain positive thoughts. The positive thoughts will lead us to have a healthy mind, reflecting our body's condition. 


\section{The Analysis of Cigarette Advertisement}

The advertisement the theme of cigarette above carries two verbal signs. The first verbal sign is "Filter your life" which denotes literally removing something in our life through a filter. The term filter in the advertisement, is associated with the filter as in a cigarette. The filter in the cigarette is generally made of cellulose acetate obtained from processed wood used to filter tar and nicotine from cigarette, the most dangerous substances contained in cigarettes. Based on that explanation, the statement "filter your life" implicitly conveys a message to the readers to choose more carefully the things they are about to do in their life, especially those that can directly affect their body. It is by making sure it is the best for them and healthy for their body and avoiding the things that is negative and harmful. In association with the theme of the advertisement, one of the things that people need to avoid is smoking cigarettes because the habit can damage their health overtime.

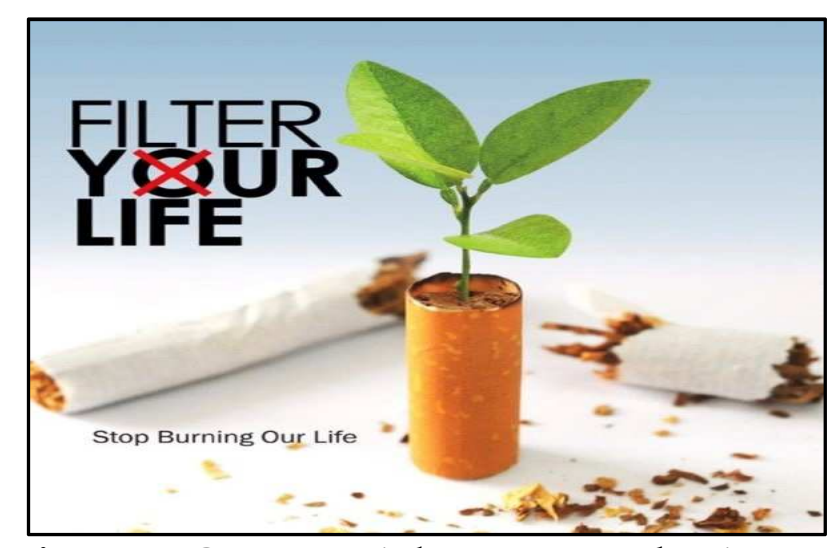

Figure 4. Cigarette Advertisement by Ateriet

(Source: pinterest.com)

The second verbal sign is "Stop burning your life". The statement denotes to literally stop causing something that can damage your life. According to the context, the term "burning" is closely associated of smoking a cigarette. Therefore, the statement implicitly carries the message to stop doing harmful things for our body, such as smoking cigarettes. The substances contained in cigarettes are harmful to the body because the substances, especially tars, will increase our lungs' risk of lung cancer. It indeed is a something that is scary and not wanted by many people, that is why we should promote a healthy lifestyle in which including not smoking cigarettes.

The advertisement carries four nonverbal signs. The first nonverbal sign is a sprout growing from a filter of cigarette which denotes a sprout of a plant growing inside a filter of a cigarette. In relation to the theme, the 
sprout represents the new beginning of life while the cigarette filter becomes the place to grow. Therefore, it implicitly delivers the message to help the readers who are still smoking to realize the danger of smoking and remind them that there is still the opportunity to change for a better life. In other words, we must allow ourselves to grow beautifully like a green sprout like in the advertisement.

The second nonverbal sign is the picture of cigarettes that have been torn apart, which denotes literally the same thing. The torn cigarette refers to the state of moving forward after realizing the destruction caused by smoking cigarettes to our body. It implies the readers who can stop smoking need to keep moving forward and not doing the same mistake again in the future. In other terms, we need to realize that the cigarette has bad impact for our body especially our lungs and that is why we must leave them.

The third nonverbal sign is the combination of blue and white color as the background. The blue color denotes having color the same as the sea or the sky while white color denotes having the same color as the snow or milk. In relation with the color term, Wierzbicka (1996) states that blue is the color that used to describe health, healing, calm, understanding and softness and white color is associated with purity, goodness, innocence, and virginity. According to the theme of advertisement, blue color is used to describe understanding and health, meanwhile white describes goodness. Therefore, the combination of both color in the advertisement above implicitly telling the readers to understand the danger caused by smoking cigarettes and always maintain their health by doing the right thing for their body.

The last nonverbal sign is the prohibition symbol $\mathrm{O}$ which denotes as prohibition. The sign implies that people are prohibited to smoke considering the effect that can cause to their body. In addition, people need to also remind the others who smoke about the danger of smoking. Aside from addiction, smoking can increase the risk of fatal diseases because of the cigarette's substances contained in the cigarette. Therefore, if we want to be healthy and avoid the risk of fatal diseases, we should never smoke a cigarette in the first place.

\section{CONCLUSION}

The current study focuses on describing the hidden messages in several Public Health advertisements found in Pinterest. Among the 4 data, this study found 8 verbal signs and 12 nonverbal signs in which each of those data carries a hidden message. Generally, the public health advertisements found in Pinterest carry a message in which to promote a healthy lifestyle to the readers. Through the verbal and nonverbal signs that have been analyzed, it can be concluded that the advertisements carry various hidden messages. The first advertisement delivers a message to 
the readers to choose their food wisely by eating healthy food for the body to work properly. The second advertisement encourages the readers to adopt healthy lifestyle in their life which including, exercise regularly, sunbathing in the morning and eating a healthy kind of food to be healthy. The third advertisement reminds people to always maintain their mental health by always thinking positively because the health of their mind is directly affecting the health of their body. The fourth advertisement prohibits the readers from adopting a habit or lifestyle that is harmful for their body such as smoking cigarettes, considering the danger it may cause in the future. These messages are very beneficial for the readers to increase their knowledge about promoting healthy lifestyle in their lives.

\section{REFERENCES}

Barthes, R. 1977. Elements of Semiology.Hil and Wang, New York: A Division of Farrar, Straus and Giroux.

Chandler, D. 2002. Semiotics: The Basic. New York, USA: Routhledge.

Danesi, Marcel. 2010. Pesan Tanda dan Makna : Buku Teks Dasar Mengenai Semiotika dan Teori Komunikasi. Yogyakarta: Jalasutra

De Saussure, F. 1972. Cours de Linguistique Générale. Paris: Payot

Pinterest, 2020. All about Pinterest. Retrieved October 20, 2020, from http:/ / www.pinterest.com/en/guide/all-about-pinterest

Sobur, A.. 2004. Semiotika Komunikasi. Bandung: Remaja Rosdakarya.

Wierzbicka, A. 1996. SEMANTICS: Primes and Universals. New York: Oxford University Press.

Wikipedia, n.d. Definition of advertisement. Retrieved March 20, 2021, from http:/ / wikipedia.com 